\title{
CADERNOS DE PSICOLOGIA SOCIAL DO TRABALHO: METASSÍNTESE DA PRODUÇÃO PUBLICADA EM DUAS DÉCADAS
}

\author{
CADERNOS DE PSICOLOGIA SOCIAL DO TRABALHO: \\ METASSÍNTESIS DE LA PRODUCCIÓN \\ PUBLICADA EN DOS DÉCADAS \\ A METASTNTHESIS ON THE SCHOLARLY JOURNAL \\ CADERNOS DE PSICOLOGIA SOCIAL DO TRABALHO \\ IN ITS TWO DECADES OF EXISTENCE
}

\author{
Juliano Almeida Bastos ${ }^{1}$ Flávia Manuella Uchôa de Oliveira ${ }^{2}$ \\ ${ }^{1}$ Centro Universitário Tiradentes (UNIT), Centro de Psicologia Aplicada, Maceió/AL, Brasil \\ ${ }^{2}$ Universidade de São Paulo, São Paulo/SP, Brasil
}

\begin{abstract}
RESUMO: O objetivo deste artigo é a apresentação da metassíntese elaborada a partir da revista Cadernos de Psicologia Social do Trabalho (CPST). A metassíntese compreende um método de revisão, que visa a sistematizar, descrever e conduzir o material em estudo a uma análise interpretativa dos resultados. É um modo de apresentar a história da revista e de resgatar o desenvolvimento da Psicologia Social do Trabalho (PST) no Brasil. Para a realização da metassíntese, a revista CPST foi a um só tempo o objeto de estudo e a fonte utilizada. Optou-se por considerar todos os documentos publicados na revista, submetendo-os a cinco etapas de tratamento: Exploração, Refinamento, Cruzamento, Descrição e Análise. O tratamento desses documentos permitiu corroborar os marcos fundantes e estruturantes da Psicologia Social do Trabalho. Pode-se afirmar que a vitalidade e a potência dos fenômenos do trabalho exigiram da Psicologia uma postura distinta daquela que equivalia de maneira equivocada trabalho e emprego.

PALAVRAS-CHAVE: Cadernos de Psicologia Social do Trabalho; Metassíntese; Psicologia Social do Trabalho.
\end{abstract}

RESUMEN: Este artículo presenta una metasíntesisenla revista Cadernos de Psicologia Social do Trabalho (CPST). La metasíntesis comprende un método de revisión que tiene como objetivo sistematizar y describir el material estudiado, lo que lleva a un análisis interpretativo de los resultados. Es forma de presentar la historia de la revista y analizar el desarrollo de la Psicología Social Del Trabajo (PST) en Brasil. Para lograr nuestros objetivos, utilizamos la revista como objeto y como fuente de datos. Decidimos trabajar con todos los documentos publicados en la revista, sometiéndolos a un tratamiento de cinco etapas: Exploración, Refinamiento, Cruzamiento, Descripción y Análisis. El tratamiento dado a los documentos nos permitió corroborar con los hitos fundacionales y estructuradores de la Psicología del Trabajo Social. Podemos indicar que la vitalidad y la potencia de los fenómenos laborales exigieron a la psicología una actitud diferente hacia las nociones de trabajo y empleo.

PALABRAS CLAVE: Cadernos de Psicologia Social do Trabalho; metasíntesis; Psicología Social del Trabajo.

ABSTRACT: This paper presents a metasynthesis on the scholarly journal Cadernos de Psicologia Social do Trabalho (CPST) in its two decades of existence. The metasynthesis comprises a review method that aims to systematize and describe the studied material, leading to an interpretative analysis of the results. This is a way to present the history of the Journal and also to analyze the development of the discipline of Social Psychology of Work (PST) in Brazil. In order to accomplish our objectives, we used the journal as the object of study and as the source of data. We decided to work with all the documents published by the journal, submitting them to a five-stage process: exploration, refinement, crossing, description and analysis. The treatment given to the journal's collection allowed us to corroborate with the founding and structuring milestones of Social Work Psychology. We can indicate that the vitality and potency of the work phenomena demanded from Psychology a different attitude towards the notions of work and employment.

KEY WORDS: Cadernos de Psicologia Social do Trabalho; Metasynthesis; Social Psychology of Work. 


\section{Introdução}

O objetivo deste artigo é a apresentação da metassíntese elaborada a partir dos 19 volumes editados pela revista Cadernos de Psicologia Social do Trabalho (CPST) em suas duas décadas de existência completadas em 2018. Trata-se, portanto, de um modo de apresentar a história da revista e, para além disso, resgatar o desenvolvimento da disciplina Psicologia Social do Trabalho (PST) no Brasil. Percorremos, nesta pesquisa, os principais temas abordados, a diversidade de referenciais teórico-metodológicos utilizados, os segmentos da população trabalhadora estudados, dentre outros elementos cuja apreciação analítica permitiu reconhecer o estado atual dessa disciplina em nosso país por meio da CPST.

Ao considerarmos o cenário nacional das publicações científicas nas últimas décadas e, paralelamente, o desenvolvimento da revista, duas questões introdutórias se apresentam: a primeira diz respeito aos vários esforços empreendidos para aperfeiçoar e garantir a qualidade no conteúdo e nos meios de difusão da produção científica. Tal desenvolvimento se deu, sobretudo, por meio da sistematização de processos de avaliação, que, a despeito das críticas que receberam, vêm alcançando resultados positivos em seus propósitos (Costa \& Yamamoto, 2008; Costa, Amorim, \& Costa, 2010; Souza, Costa, Macedo, Segantini, \& Baia, 2013; Yamamoto et al., 2002), tendo a Cadernos sofrido influência direta desse processo. A segunda questão refere-se à singularidade da proposta editorial que caracteriza a Cadernos. Observa-se que desde sua origem até hoje a revista possui uma abertura para a publicação das mais variadas formas de expressão da produção científica. Tal singularidade está expressa desde sua fundação, no ano de 1998.

Em um primeiro momento, a revista transforma-se em um espaço para a publicação dos alunos do curso de graduação do Instituto de Psicologia da Universidade de São Paulo. Nos primeiros volumes, os trabalhos de pesquisa exploratória (ou "minipesquisas") solicitados aos alunos no âmbito da disciplina Psicologia Social do Trabalho e dos Processos Organizativos - ministrada em inédita articulação entre docentes e técnicos do Centro de Psicologia Aplicada ao Trabalho (CPAT) no IPUSP — eram privilegiados.

O objetivo era disponibilizar um repositório para que as pesquisas desenvolvidas por esses alunos fossem catalogadas e publicadas, facilitando assim o acesso a esse material. A revista tornou-se assim alicerce para o desenvolvimento de pesquisas e para a formação de pesquisadores na disciplina Psicologia Social do Trabalho. Entendemos que os criadores da CPST, Leny Sato e Fábio Oliveira, esboçaram uma intenção adstrita ao âmbito da produção científica.

Em meados dos anos 2000, a Cadernos expande seus limites e passa a publicar artigos, ensaios, relatos de pesquisa e de experiência, entrevistas e conferências, em que passaram a figurar pesquisadores experientes de diferentes centros de pesquisa do Brasil e de outros países, com diversas contribuições originais para a compreensão das questões relativas ao trabalho.

Considerando-se seu propósito inicial, sua expansão e aperfeiçoamento e ainda a abertura para a publicação de diversas formas de expressão, parece-nos razoável afirmar que a Cadernos vem cumprindo um importante papel no que se refere à produção científica que toma o trabalho como objeto de investigação psicológica. Mais que isso, a revista vem contribuindo para consolidação e difusão de um modo peculiar no interior da Psicologia de abordar o trabalho e os processos organizativos. 
Partindo das leituras propostas pela Psicologia Social produzida no Brasil, sobretudo em sua leitura crítica (Coutinho, 2015; Esteves, Bernardo, \& Sato, 2017), a PST procura compreender os problemas sobre os quais se debruça como fenômenos psicossociais, nos quais o trabalho é categoria central de análise e os trabalhadores são agentes protagonistas na produção do conhecimento. Ademais, esse modo peculiar de abordar o trabalho não se reduz e nem se restringe a um padrão teórico-metodológico de produção do conhecimento (Bernardo, Sousa, Pinzón, \& Souza, 2015; Bernardo, Oliveira, Souza, \& Sousa, 2017; Sato, Oliveira, \& Bernardo, 2008).

Por ser um dos alicerces do desenvolvimento da PST e pela riqueza da produção científica publicada em suas duas décadas, a CPST torna-se uma fonte relevante para a compreensão das relações entre psicologia e trabalho no Brasil. Passamos a examinar a importância dessa revista mais de perto a partir da próxima sessão.

\section{Método}

Os estudos de revisão configuram-se como importante instrumento para a avaliação e o reconhecimento do desenvolvimento dos rumos assumidos pela investigação científica em determinado campo do conhecimento. Nesse sentido, a metassíntese compreende um método de revisão, que visa a sistematizar, descrever e conduzir o material em estudo a uma análise interpretativa dos resultados (Noblit \& Hare, 1988 conforme Espíndola \& Blay, 2006; Sampaio \& Mancini, 2007; Sandelowski, Docherty, \& Emden, 1997; Sandelowski \& Barroso, 2003). A categorização das informações, através de critérios claros e rigorosos, concorre para a proposição de sínteses que, por sua vez, promovem novas compreensões a partir das conexões estabelecidas no processo de pesquisa.

A metassíntese pode, portanto, ser caracterizada como uma estratégia metodológica, que proporciona a interpretação dos resultados encontrados em pesquisas realizadas, numa área determinada do conhecimento, ou em diferentes áreas que mantenham um objeto de interesse comum. Essa interpretação pretendida deve conduzir a uma análise crítica da produção científica e disponibilizar novo conhecimento, a partir das articulações possíveis entre os resultados já encontrados. (Oliveira, Trancoso, Bastos, \& Canuto, 2015)

Canuto (2017), Bastos e Oliveira (2016), Oliveira, Lima e Morais (2016) e Trancoso e Oliveira (2014) apontam alguns critérios de partida para a realização de uma metassíntese, dentre os quais se destacam a definição do objeto a ser investigado, das fontes a serem consultadas e dos tipos de documento a serem estudados. No caso deste estudo, objeto e fonte encontram-se fundidos, tendo em vista que a revista Cadernos de Psicologia Social do Trabalho é, a um só tempo, o objeto de estudo e a fonte utilizada. Quanto ao tipo de documento, dentre as diferentes modalidades que a revista publica, optou-se por considerar todos os documentos publicados, de modo a abarcar a multiplicidade existente e evidenciar o que dela emerge.

Quanto ao caráter processual necessário para o desenvolvimento da metassíntese, são sugeridas diferentes etapas: Exploração, Refinamento, Cruzamento, Descrição e Análise (Bastos, 2014). A partir dessas referências, neste estudo foram realizadas as fases de Exploração, Descrição e Análise. Os procedimentos utilizados em cada fase e os resultados alcançados são descritos a seguir. 


\section{Resultados}

\section{Fase de Exploração}

Essa fase corresponde ao primeiro contato com o material a ser analisado. Entre os meses de abril de 2016 a janeiro de 2017 procedeu-se o acesso à fonte estabelecida, a própria revista, CPST, em seu repositório virtual. Confirmada a disponibilidade de todos os 19 volumes, foram identificados 31 números e 269 publicações entre o ano de lançamento da revista, 1998, e o primeiro semestre de 2016.

Observa-se que, a partir de 2006, a Cadernos passou a publicar dois números por ano, sendo que, nos anos de 2013 e de 2014, além dos dois números anuais, foram publicados mais um número especial por ano. Em 2013, o número especial foi editado com vistas a publicar os textos produzidos e apresentados no I Colóquio Internacional de Clínica da Atividade. Já em 2014, o número especial publicou uma tradução do $n^{\circ} 15$ da Nouvelle Revue de Psychosociologie, revista semestral do CIRFIP (Centre International de Recherche, Formation et Intervention Psychosociologiques). Em 2014, a partir do número 2 do volume 17 , a revista suspendeu sua versão impressa, passando, desde então, a disponibilizar seus números em meio eletrônico, mantendo a regularidade e a disponibilidade das publicações.

Ainda nessa fase, foi produzido um quadro geral com os dados disponíveis nos documentos acessados. Para composição desse quadro foram lidos os títulos, os resumos e as palavras-chave de todos os 269 documentos. Com esse procedimento foi possível identificar e catalogar por volume e por número as seguintes informações: título, autoria, palavras-chave, tipo de publicação, eixo temático, método utilizado, segmento de trabalhadores pesquisados e o referencial teórico (quando apresentado). O levantamento desses dados mostrou-se crucial para as demais fases.

\section{Fase de Descrição}

Essa fase compreende uma descrição detalhada do material localizado na fase anterior. Aqui as informações levantadas nos 269 documentos identificados são apresentadas em categorias descritivas, o que permite uma apreciação panorâmica acerca da produção da revista. Descrevemos esses documentos em cinco categorias: tipo de documento, eixo temático, referenciais metodológicos, segmento de trabalhador pesquisado e referenciais teóricos.

\section{Tipo de documento}

As 269 publicações localizadas foram categorizadas quanto ao tipo de documento, conforme descrito na Figura 1. 


\section{Figura 1: Tipo de Publicação}

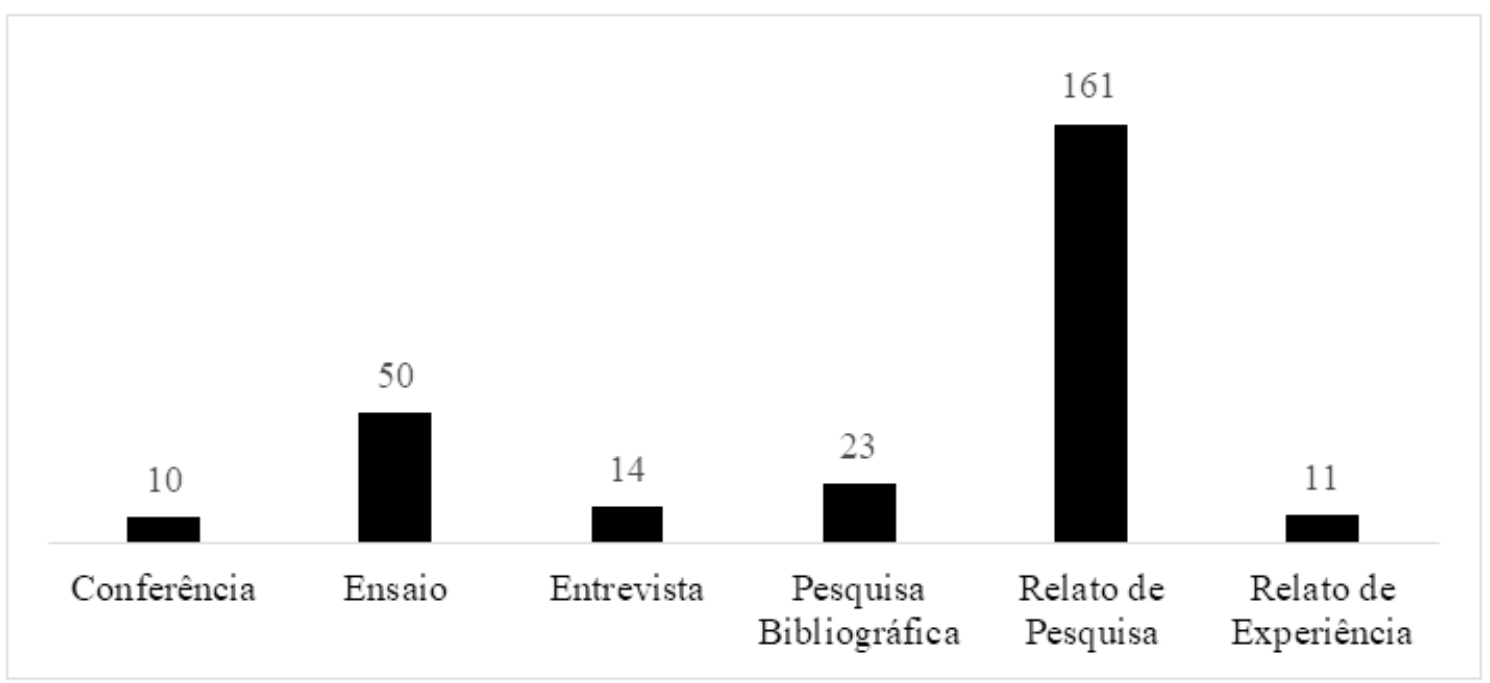

A identificação do tipo de documento publicado permite reconhecer a diversidade de material que compõe o acervo da revista, o que retrata a abertura característica da política editorial da Cadernos. Como se observa na Figura 1, os artigos que apresentam relato de pesquisa aparecem em maior volume. Em seguida, aparecem os ensaios, as pesquisas bibliográficas, as entrevistas, os relatos de experiência e as conferências.

\section{Eixo temático}

Em uma tentativa metodológica de organização dos documentos, decidimos compor os eixos temáticos considerando dois critérios: o primeiro refere-se à predominância da temática no conteúdo do artigo, e o segundo refere-se à informação explícita apresentada no artigo quanto ao objeto de estudo, presente ou no título ou no resumo ou, ainda, nas palavras-chave. Alguns artigos poderiam ser inseridos em mais de um eixo tanto pela impossibilidade de separação de uma temática de outra quanto pela diversidade de temáticas que surgem em um mesmo trabalho.

A diversidade de tipos de documentos aliada à diversidade de expressões utilizadas pelos autores para referirem-se aos seus objetos de estudo dificultou a composição de categorias. No esforço para agrupar os artigos para que uma síntese fosse possível, optou-se por respeitar as diferentes formas de apresentação e agrupar apenas os que apresentavam correspondência estrita em sua descrição temática. 


\section{Figura 2: Eixo Temáticos}

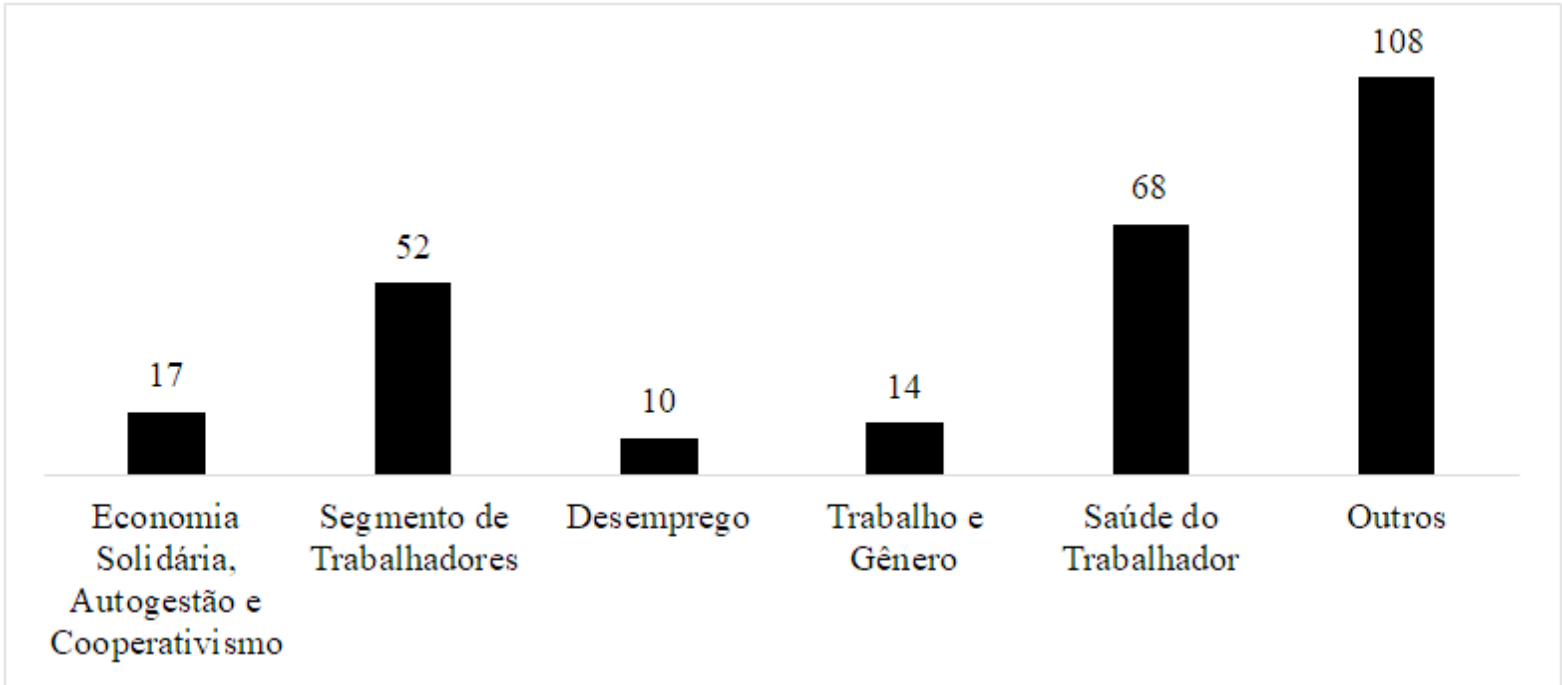

Na Figura 2 é possível observar que a saúde do trabalhador é a temática que mais se destaca. O estudo acerca das características e condições de determinados segmentos de trabalhadores compõe o segundo tema identificado. Na sequência, o eixo temático economia solidária, autogestão e cooperativismo, seguido de trabalho e gênero e desemprego. Ressalta-se ainda a categoria "outros", onde aparecem temas como: "questão social e sociabilidade capitalista"; "entrevistas de emprego"; "trabalho e sonhos"; "emoções e trabalho"; "reestruturação produtiva”, dentre outros.

\section{Referenciais metodológicos}

Avançando na descrição dos documentos, foram identificados os referenciais metodológicos. Bem como no processo de categorização dos temas, a catalogação desses referenciais foi de grande dificuldade. São muitas as expressões utilizadas pelos autores para designar os métodos ou as técnicas que utilizam, o que acaba gerando dúvidas devido à imprecisão que alguns termos carregam. A Tabela 1 apresenta uma apreciação sintética dos referenciais metodológicos citados nas publicações. 
Tabela 1: Métodos e Técnicas

\begin{tabular}{|c|c|c|c|}
\hline Método ou Técnica & Quantidade & Método ou Técnica & Quantidade \\
\hline Pesquisa Qualitativa & 16 & Construcionismo Social & 2 \\
\hline Pesquisa Qualitativa e Quantitativa & 5 & Análise Documental & 11 \\
\hline Etnografia & 5 & Questinário & 10 \\
\hline Entrevista & 61 & Análise de Conteúdo & 3 \\
\hline Psicodinâmica do Trabalho & 5 & Estatística Descritiva & 2 \\
\hline Ergonomia & 3 & Análise de Filme & 2 \\
\hline Estudo de Caso & 7 & Análise Qualitativa & 2 \\
\hline Pesquisa Intervenção & 6 & Clínica da Atividade - Oficina de Fotos & 2 \\
\hline Grupo Focal & 5 & Análise Semântica - Programa Alceste & 2 \\
\hline Análise do Discurso & 5 & Comunidade Ampliada de Pesquisa (CAP) & 2 \\
\hline Observação & 25 & Pesquisa Exploratória & 21 \\
\hline Revisão Bibliográfica & 10 & Método de Interpretação de Sentidos & 2 \\
\hline Inventário & 3 & Outros & 38 \\
\hline Análise Coletiva dos & 2 & Não apresentam & 2 \\
\hline Acidentes de Trabalho & & & 2 \\
\hline
\end{tabular}

Observa-se que as categorias foram compostas com expressões que aparecem mais de uma vez, sendo agrupadas na categoria "outros" as expressões que apareceram apenas uma vez, tais como: "Análise argumentativa", "Dispositivo baseado na construção de saberes", "Análise das interações", dentre outras. As especificidades ou subdivisões tipológicas de alguns métodos ou técnicas foram aqui agrupadas em uma mesma categoria, como por exemplo: "Entrevista semiestruturada", "Entrevistas em profundidade" e "Entrevista aberta", aparecem como "Entrevista".

\section{Segmento de trabalhadores}

A identificação dessa categoria informa acerca da população de interesse ou para quem se voltam os estudos. A Tabela 2 traz um panorama dos segmentos da população trabalhadora que aparecem nas publicações da Cadernos.

Tabela 2: Segmento de Trabalhadores

\begin{tabular}{|c|c|c|c|}
\hline Segmento & Quantidade & Segmento & Quantidade \\
\hline Metalúrgicos & 5 & Teleatendentes/ Teletrabalhadores & 4 \\
\hline Camelôs/ Ambulantes & 3 & Catadores de Material Reciclável & 4 \\
\hline Militares & 3 & Profissionais do Sexo & 2 \\
\hline Cooperados & 12 & Servidores Públicos & 9 \\
\hline $\begin{array}{c}\text { Trabalhadores da Extração de Ro- } \\
\text { chas }\end{array}$ & 4 & Estudantes & 9 \\
\hline $\begin{array}{c}\text { Trabalhadores da Saúde } \\
\text { Trabalhador Rural }\end{array}$ & 21 & Bancários & 5 \\
\hline Trabalhadores da Educação & 4 & Feirantes/ Trabalhadores Infor- & 3 \\
\hline Psicólogos & 15 & $\begin{array}{c}\text { Trabalhadores do Abate de Ani- } \\
\text { mais }\end{array}$ & 2 \\
\hline Guardas Municipais & 4 & Trabalhadores da Construção Civil & 2 \\
\hline
\end{tabular}


Foram 50 segmentos de trabalhadores catalogados em 143 dos 269 artigos publicados, dentre os quais se destacam o dos "Trabalhadores da Saúde", o dos "Trabalhadores da Educação" e o dos "Cooperados".

A variedade de segmento de trabalhadores estudados indica que os estudos produzidos se ocupam dos trabalhadores em suas diversas áreas de atuação, bem como condição ou situação. Na categoria “outros”, por exemplo, estão presentes: "portuários”, "mulheres em posição de liderança”, "trabalhadores com transtorno mental grave”, "travestis de baixa renda”. É importante pontuar que o trabalhador que comparece nos estudos publicados na Cadernos não se circunscreve ao contexto do emprego.

\section{Referenciais teóricos}

A última categoria descritiva diz respeito aos referenciais teóricos citados pelos autores nas publicações. A Tabela 3 retrata a diversidade de referenciais teóricos citados.

\section{Tabela 3: Referenciais Teóricos}

\begin{tabular}{|c|c|c|c|c|c|}
\hline Referencial & Quantidade & Referencial & Quantidade & Referencial & Quantidade \\
\hline $\begin{array}{c}\text { Representações } \\
\text { Sociais }\end{array}$ & 4 & $\begin{array}{c}\text { Psicossociologia do } \\
\text { Trabalho }\end{array}$ & 3 & Psicossociologia & 3 \\
\hline $\begin{array}{c}\text { Psicodinâmica do } \\
\text { Trabalho }\end{array}$ & 16 & Clínica da Atividade & 14 & Psicologia Social & 2 \\
\hline Psicanálise & 6 & $\begin{array}{c}\text { Construcionismo } \\
\text { Social }\end{array}$ & 2 & Teoria Crítica & 2 \\
\hline Ergologia & 10 & $\begin{array}{c}\text { Arqueologia (Michel } \\
\text { Foucault) }\end{array}$ & 3 & Outros & 27 \\
\hline Ergonomia & 5 & Teoria Sócio-Técnica & 2 & Não apresentam & 128 \\
\hline
\end{tabular}

Foram 40 referenciais citados, sendo o mais citado a Psicodinâmica do trabalho, seguido da Clínica da Atividade, da Ergologia, da Psicanálise, Ergonomia e Teoria das Representações Sociais. Estão agrupados na categoria "outros" referenciais como: "Sociologia do cotidiano", "Teoria das paixões", "Teoria de E. Pichon-Rivière”. Chama atenção o número de publicações que não apresentam referencial teórico. Excetuando-se as entrevistas, as conferências e a maioria dos ensaios, são 128 publicações que não fazem referência a uma teoria de base.

A fase de Descrição proporcionou uma visão panorâmica acerca da produção da $C a$ dernos, ao mesmo tempo em que levantou algumas questões que merecem um exame mais acurado. É isso que se propõe na fase seguinte deste estudo.

\section{Fase de Análise}

Esta última fase compreende o que Sandelowski, Docherty e Emden (1997) indicam como a análise das informações a partir de um olhar em perspectiva, estabelecendo-se uma relação dialética entre aproximação e distanciamento das informações, ou, como prefere Bardin (2002), flutuação e aprofundamento na leitura destas. Trata-se do exercício de uma leitura, a um só tempo, dispersa e vigilante. 
É esta fase que viabiliza a metassíntese. É na análise que o pesquisador articula as informações, estabelece conexões, confronta os dados apresentados, enfim, ultrapassa o conteúdo de cada documento para alcançar uma compreensão que está entre estes. (Bastos, 2014, p. 59)

Considerando o volume de informações e a complexidade que essa fase enseja, uma vez que exige a leitura integral dos documentos a serem analisados, torna-se necessária a composição de uma amostra que torne o trabalho exequível.

Assim, dois caminhos foram trilhados. Em um primeiro momento, optamos por analisar os artigos mais visualizados de acordo com a lista divulgada na página virtual da revista (Cadernos de Psicologia Social do Trabalho, 2017). Esses foram escolhidos por indicarem a difusão do conhecimento promovido pela Cadernos, pois apresentam um padrão de busca que retrata como esta vem sendo vista enquanto fonte de produção acadêmica.

Além desse recorte, optamos também pela leitura dos artigos que apresentavam entre as suas palavras-chave as expressões "Psicologia social" e/ou "Psicologia do Trabalho" e/ou, finalmente, "Psicologia social do trabalho". Tal recorte teve como intenção localizar artigos que apresentassem as características dos estudos que, a partir da psicologia social, se voltam para o trabalho sem se restringirem aos temas gerenciais ou circunscritos à organização.

Quanto às publicações mais acessadas, a revista disponibiliza uma lista com dez artigos. Esses foram publicados no período compreendido entre 2003 e 2011. São 04 ensaios, 04 relatos de pesquisa, 01 resenha e 01 entrevista. No que se refere ao material localizado a partir das palavras-chave "Psicologia social", "Psicologia do trabalho" e "Psicologia social do trabalho", foram 18 artigos encontrados. Publicados entre os anos de 1999 e 2016, estão 12 relatos de pesquisa, 03 relatos de experiência e 03 ensaios.

Ao analisarmos o conjunto composto pelos dois grupos de documentos, justapostos e lidos em perspectiva (sequencialmente ou em idas e vindas e repetidamente), os artigos publicados apresentaram categorias transversais. É essa rede de pontos transversais que efetivamente constitui a metassíntese, nosso objetivo central neste estudo.

Entre um padrão de acesso e um padrão de conteúdo publicado na revista, três categorias compõem nossa análise e conformam a metassíntese: desemprego e as várias formas de trabalhar; economia solidária, autogestão e cooperativismo; e saúde do trabalhador.

\section{Desemprego e as várias formas de trabalhar}

Embora o desemprego e outras formas de trabalho sempre tenham sido uma realidade para muitos trabalhadores brasileiros (Pochmann, 2006, 2008), a Psicologia que toma o trabalho como campo de investigação (e poderíamos afirmar as ciências sociais em geral) pouca atenção dedicou a esse fenômeno até o final do século passado (Spink, 2017). Na perspectiva da Psicologia brasileira, os estudos do trabalho focalizaram o trabalho urbano e assalariado, sobretudo priorizando as demandas de gestão do trabalho, constituindo-se muito mais como uma "Psicologia do Emprego", mais comprometida com os interesses gerenciais do que propriamente como uma Psicologia do trabalho (Bernardo, Sousa, Pinzón, \& Souza, 2015; Bernardo, Oliveira, Souza, \& Sousa, 2017; Sato \& Bernardo, 2008; Spink, 2009). 
Os processos de flexibilização e desregulamentação dos contratos de trabalho e de desassalariamento (Pochmann, 2006, 2008) conformaram uma realidade que não só transformou como multiplicou as possibilidades de inserção de homens e mulheres no mundo do trabalho, este já não restrito às configurações de emprego. A rapidez com que tais mudanças aconteceram praticamente obrigou os estudiosos do trabalho em suas várias disciplinas a buscar novas ferramentas conceituais que pudessem dar conta da diversidade de situações de trabalho que passaram a ocorrer. Ricardo Antunes (2009), para citar um exemplo, propõe a expressão "a-classe-que-vive-do-trabalho".

Em um primeiro movimento, amplia-se o campo de atuação ao compreender-se que, mesmo fora da relação de emprego, também há trabalho, ou também há mulheres e homens trabalhadores (Sato, 2012).

Nessa direção, passa-se a considerar as nuances e repercussões do fenômeno do desemprego à vida dos trabalhadores numa perspectiva psicossocial e, mais que isso, passa-se a considerar o ponto de vista daqueles que vivenciam o desemprego ou as dificuldades para alcançá-lo, como aparece nos estudos publicados na Cadernos por Ackermann et al. (2005), ${ }^{1}$ Terra et al. $(2006)^{2}$, Farina e Neves $(2007)^{3}$ e Violante e Leite (2011) .

Também a partir da consideração da temática do desemprego como objeto de investigação e intervenção psicológicas, observa-se o desdobramento em novos campos de atuação que passaram a ser centrais no desenvolvimento da Psicologia social do trabalho, tais como o campo da Economia Solidária (Esteves, Bernardo, \& Sato, 2017) e o do Trabalho informal ou o reconhecimento da Polimorfia do trabalho (Sato, 2017), articulando-se ainda com o campo da Saúde do trabalhador (Esteves, Bernardo, \& Sato, 2017; Sato, Lacaz, \& Bernardo, 2006) e na relação entre saúde mental e trabalho (Seligmann-Silva, 2011).

O estudo publicado por Salvitti, Viegas, Mortada e Tavares (1999, p. 1) $)^{5}$ ilustra esse desdobramento. Ao adotarem como questão de partida se "seria o trabalho do camelô uma alternativa de trabalho entre outras possíveis ou a única saída para o desemprego?”, os autores apontam como esse fenômeno está presente nas transformações e nas múltiplas formas de trabalho que se tornaram objeto de interesse da Psicologia social do trabalho.

Suzana Guerra Albarnoz, em dois de seus ensaios publicados na Cadernos, apresenta a obra de Paul Lafargue (2008) $)^{6}$ e Axel Honneth (2011) $)^{7}$, e articula o pensamento desses autores com as formas contemporâneas de organização do trabalho. Ela assim comenta:

O sentido de "desemprego" é hoje inteiramente outro, mesmo em sociedades chamadas do primeiro mundo. Não se trata mais de um período transitório que o operário atravessa, entre uma situação de emprego e outra, mas de uma mudança de caráter global, societário, em que os empregos não existem mais na mesma quantidade na área da produção material. (Albornoz, 2008, p. 13)

E ainda: "A realidade das transformações do trabalho convida a repensar a dinâmica das relações sociais nas quais se dão as redes de reconhecimento intersubjetivo" (Albarnoz, 2011, p. 129). Note-se que a categoria desemprego se articula às demais categorias priorizadas nesta análise, de modo que a apresentação em separado cumpre apenas a função de sublinhar as mudanças que se estabelecem no olhar da Psicologia para os fenômenos do trabalho. 


\section{Economia Solidária, Autogestão e Cooperativismo}

O movimento nomeado por Paul Singer (2002) de Economia Solidária tem sido apontado por diversos autores (Andrada, 2006, 2013; Esteves, Bernardo, \& Sato, 2017) como uma resposta alternativa dos trabalhadores à falta de emprego e à necessidade de gerar renda através do trabalho. Esses passaram a se organizar em torno de empreendimentos autogestionários que seguem uma lógica peculiar, tal como aponta Cris Andrada:

$\mathrm{Na}$ relação de trabalho autogestionária, os trabalhadores organizam-se democraticamente para a construção e gestão de um empreendimento que pertença a todos, política e economicamente. Esta relação baseia-se, por princípio na posse e na socialização dos meios e dos resultados da produção, na gestão democrática e na fundamental condição de igualdade entre os membros. (Andrada, 2013, p. 8)

Com essa dinâmica peculiar e com muitas questões a serem compreendidas, os espaços onde se desenvolviam os processos organizativos que se inscreviam nesse modelo alternativo de trabalho rapidamente constituíram-se campo de atuação (investigação e intervenção) para os psicólogos sociais interessados pelas múltiplas formas de organização dos trabalhadores no cotidiano que se estabelece para além da empresa capitalista. (Andrada, 2005, 2006; Esteves, 2002; Sato \& Esteves, 2002).

Em artigo publicado na Cadernos já em 2001, Iolanda Évora ${ }^{8}$ analisava o tema a partir da experiência de Cabo Verde, onde aponta os aspectos sócio-históricos, político-ideológicos e geoeconômicos que comparecem no cotidiano do trabalho autogestionário, ressaltando o processo social que antecede e sobrepõe-se aos programas de governo, de modo que o que vem a definir o que é ou como se organiza essa modalidade de organização do trabalho é efetivamente "o que as pessoas fazem e não o contrário" (Évora, 2001, p. 11).

Roa e Hur $(2010)^{9}$ apresentam a experiência de um grupo de geração de renda em uma instituição educativa como alternativa para alguns alunos desempregados conseguirem manter-se estudando, uma vez que, mesmo conseguindo emprego, teriam que submeter-se à jornada de trabalho em período a ser definido pelo empregador, por exemplo; o que poderia inviabilizar a permanência na condição de estudante. Aqui a proposta da autogestão mostra-se tanto como alternativa de viabilidade econômica como de autonomia para dispor dos tempos da própria vida, de modo que o tempo de trabalhar não viesse a impedir o tempo de estudar. O trabalho autogerido instituiu-se, nesse caso, enquanto "dispositivo político-econômico" (Roa \&Hur, 2010. p. 172).

Já a experiência relatada por Gama e Koda $(2010)^{10}$ guarda algumas semelhanças com outras experiências em que psicólogos sociais foram chamados a contribuir com os trabalhadores no sentido de lidarem com os complexos processos organizativos que caracterizam o trabalho em uma cooperativa. Nesse relato chama atenção a especificidade da compreensão construída a partir do referencial teórico utilizado, a Psicanálise.

O estudo publicado por Baratieri e Beatriz (2013) apresenta um levantamento acerca da atuação de psicólogos no campo da Economia Solidária. A própria proposição do estudo e os resultados apresentados atestam o crescimento da interface estabelecida entre a Psicologia que se interessa pelo trabalho fora da perspectiva hegemônica e os empreendimentos identificados com a Economia Solidária. Evidencia-se, ainda, a contribuição mútua que emerge dessa interface, uma vez que, no contexto democrático que caracteriza a dinâmica de trabalho nos diversos espaços que se reconhecem nesse campo, a igualdade de saberes constitui fonte de aprendizagem para todos que a eles acedem. 
A dinâmica cotidiana caracterizada pela adoção do processo organizativo autogestionário, a forma como os sócios trabalhadores negociam e produzem novos entendimentos cotidianos acerca da realidade de trabalho na qual estão inseridos e a qual ao mesmo tempo constroem, assim como as possibilidades alcançadas com o uso da etnografia em um estudo que se volta para esse tipo de compreensão são contribuições apresentadas pelo artigo de Esteves $(2013)^{11}$. O estudo traz ainda importantes ferramentas conceituais que vêm ajudando a consolidar o processo de desenvolvimento em mão dupla que se tem alcançado com a inserção da Psicologia social do trabalho nos espaços que adotam a autogestão como forma de organização do trabalho.

\section{Saúde do Trabalhador}

Do surgimento da Medicina do Trabalho até o que atualmente se denomina Saúde do Trabalhador, várias e sucessivas mudanças transcorreram e transformaram substancialmente a forma de compreender e intervir na relação trabalho - saúde. Se inicialmente o controle centrava-se na figura de um único especialista responsável por escolher homens mais aptos e cuidar para que se adequassem ao trabalho com vistas a atender aos interesses da produção; posteriormente, mas ainda com a mesma preocupação, surge a ideia de intervir no ambiente, visando a proporcionar condições de trabalho adequadas à manutenção da saúde, movimento que veio a ser denominado de Saúde Ocupacional. (Lacaz, 2007; Mendes \& Dias, 1991; Minayo-Gomes, 2011)

É de se fazer notar a semelhança entre o movimento de aproximação inicial da Medicina e da Psicologia com o mundo do trabalho, ambas comprometidas com a produtividade e empenhadas em produzir e disponibilizar conhecimento no intuito de alocar, adaptar e melhor explorar os recursos humanos no interior das organizações. Como aponta Carelli (1975), citado por Sato (2013, p. 100), "a ciência psicológica começa a ter seu campo configurado na área das organizações e do trabalho [...] como ramo da medicina”.

Somente nos anos de 1960, a partir dos movimentos sociais que marcaram a segunda metade dessa década, é que surgem na Europa e nos Estados Unidos as primeiras experiências que iriam consolidar o movimento contra-hegemônico que transformaria radicalmente a forma de pensar e atuar sobre o processo saúde e doença no trabalho. Nessa nova concepção: "trabalhadores buscam ser reconhecidos em seu saber, questionam as alterações nos processos de trabalho [...] exercitam o direito à informação e a recusa ao trabalho perigoso e arriscado à saúde” (Mendes \& Dias, 1991, p. 347).

No Brasil, mais tardiamente, a emergência do campo da Saúde do trabalhador resultou da combinação de múltiplos fatores, que, dadas as condições do momento histórico abertura política e redemocratização do país com a promulgação de uma nova constituição -, conformaram um conjunto coeso de princípios que se desdobraram em práticas movidas, no dizer de Lacaz (2007, p. 758), "por três fatores: a produção acadêmica; a programação em saúde na rede pública e; o movimento dos trabalhadores, particularmente a partir dos anos 1980."

A inserção da Psicologia no campo da Saúde do trabalhador no país é das experiências inaugurais do que mais tarde conformaria a Psicologia social do trabalho. A atuação de psicólogos sociais em equipes multidisciplinares de pesquisa mantidas por entidades sindicais e também em equipamentos de saúde pública já destinados às questões relativas à saúde do trabalhador conformam as primeiras experiências a partir das quais a Psicologia conseguiu finalmente ajustar seu olhar para enxergar os fenômenos do trabalho sob outra mirada (Bernardo et al. 2015; Sato, Lacaz, \& Bernardo, 2006). 
Os artigos cuja discussão se insere no âmbito da Saúde do Trabalhador apresentam articulação com distintos conceitos. No artigo de Martinez e Paragauay (2003) ${ }^{12}$, por exemplo, discute-se a relação entre satisfação e saúde no trabalho, reforçando-se a ideia de que em qualquer método empregado e para qualquer ação a ser empreendida a participação dos trabalhadores é ponto central a ser respeitado.

Já nos estudos de Moreira et al. (1999) ${ }^{13}$ e de Rancan e Giongo (2015) ${ }^{14}$, o comprometimento à saúde dos trabalhadores é apontado em contextos distintos. No primeiro caso, é trazida a ambiguidade vivenciada por policiais militares frente às contradições advindas das exigências que lhes são impostas pela instituição policial. Já no segundo são os trabalhadores da indústria metalmecânica que relatam suas vivências de prazer e sofrimento e as estratégias defensivas utilizadas para lidarem com o sofrimento vivenciado no trabalho. Em comum entre esses contextos, há a atenção dada às formas de organização do trabalho, aos processos de trabalho e às condições materiais para a realização do trabalho, levantadas sob o ponto de vista do trabalhador.

No artigo de Ramalho, Arruda, Sato e Hamilton (2008) ${ }^{15}$, os processos de trabalho repetitivo e monótono e a organização desse, incentivando a competitividade, são os indicadores utilizados para classificar o trabalho como penoso, sobretudo pela ausência de controle por parte do trabalhador sobre sua atividade. São os trabalhadores do teleatendimento, categoria emblemática do mundo do trabalho contemporâneo. Os autores relatam as diferentes formas de aproximação com o fenômeno, destacando-se a visita a uma central de teleatendimento e as entrevistas realizadas com o objetivo de "conhecer o ponto de vista dos trabalhadores” (Ramalho, Arruda, Sato, \& Hamilton, 2008, p. 22).

O artigo de Leny Sato (2013) - embora apresente um panorama das várias entradas a partir das quais a Psicologia, e mais detidamente a Psicologia social, passou a mirar o trabalho sob uma perspectiva distinta daquela "utilitarista" (Sato, 2013, p. 100) que caracteriza o olhar da Psicologia do Trabalho e das Organizações $\square$, evidencia um marco dessa nova mirada, ressaltando a inserção e interlocução com o campo da Saúde do trabalhador. O cotidiano de trabalho (processos e formas de organização) considerado a partir da compreensão dos trabalhadores que o vivenciam são a fonte dos objetos de interesse dessa Psicologia que tem sido denominada de Psicologia social do trabalho.

\section{Considerações finais}

O tratamento dado aos 269 documentos do acervo da CPST permitiu a análise dessa produção evidenciando elementos que atestam o desenvolvimento da revista enquanto periódico científico e o desenvolvimento de um modo ampliado de investigar, intervir e discutir os fenômenos do trabalho a partir da Psicologia. A análise empreendida possibilitou sustentar e corroborar marcos fundantes e estruturantes da Psicologia Social do Trabalho e convergem com as considerações da recente publicação do livro tex to "Psicologia Social do Trabalho" (2017). As fontes de pensamento e de práticas que compõem a PST estão em pari passu com aquelas apresentadas nas publicações da CPST. O material de duas décadas torna visível a construção desses alicerces. 
As bases da PST, conforme a CPST, colocam-se para fora do emprego, sem perdê-lo de vista como umas das formas de trabalhar. Ampliam a complexidade do mundo do trabalho, incluindo o trabalho informal, autônomo, "os bicos" e "as virações". O foco nas várias formas de criar e exercer o trabalho mostra uma ruptura com a preocupação excessiva da psicologia com o mundo do emprego e recoloca a discussão de outras formas de inserção no trabalho e na economia.

Por estar além do emprego, outras leituras e ferramentas também tiveram de ser construídas no desenvolvimento da PST. A leitura próxima a outras ciências sociais e à medicina social da América Latina demonstram o esforço de ampliar a compreensão de trabalho, superando a experiência do emprego e da relação "empregador-empregado". Os estudos em Saúde do Trabalhador, Autogestão e a Economia Solidária tomam espaço nesse esforço.

Por fim, ressalta-se que a Cadernos da Psicologia Social do Trabalho foi um dos lugares de "extrema importância na busca de uma legitimação de novas ideias e práticas" (Spink, 2017 , p.10). A revista é um instrumento ativo e reflexivo da construção da Psicologia Social do Trabalho.

\section{Notas}

1 Ackermann K., Amaral, M. A., Silva, J. C. B., Geraldes, A. L., Lima, T. N., Júnior, M. L., Mendes, A., \& Scandiucci, G. (2005). O desemprego do tempo: narrativa de trabalhadores desempregados em diferentes ambientes sociais. Cadernos de Psicologia Social do Trabalho, 8(1), 1-27.

2 Terra, C. P., Carvalho, J. A. S., Azevedo, J. E. A., Venezian, L. A., \& Machado S. B. (2006). Desemprego: discurso e silenciamento - um estudo com clientes de um serviço de aconselhamento psicológico. Cadernos de Psicologia Social do Trabalho, 9(1), 33-51.

3 Farina, A. S. \& Neves, T. F. S. (2007). Formas de lidar com o desemprego: possibilidades e limites de um projeto de atuação em psicologia social do trabalho. Cadernos de Psicologia Social do Trabalho, 10(1), 21-36.

$4 \quad$ Violante, R. R. \& Leite, L. P. (2011). A empregabilidade das pessoas com deficiência: uma análise da inclusão social no mercado de trabalho do município de Bauru, SP. Cadernos de Psicologia Social do Trabalho, 14(1), 73-91.

5 Salvitti, A., Viégas, L. S., Mortada, S. P., \& Tavares, D. S. (1999). O trabalho de camelô: trajetória profissional e cotidiano. Cadernos de Psicologia Social do Trabalho, 2(1), 1-23. 
6 Albornoz, S. G. (2008). Sobre o direito à preguiça de Paul Lafargue. Cadernos de Psicologia Social do Trabalho, 11(1), 1-17.

7 Albornoz, S. G. (2011). As esferas do reconhecimento: uma introdução a Axel Honneth. Cadernos de Psicologia Social do Trabalho, 14(1), 127-143.

8 Évora, I. M. A. (2001). Cooperativa: política de Estado ou cotidiano. O caso de Cabo Verde. Cadernos de Psicologia Social do Trabalho, 4(1), 9-30.

9 Roa, F. A. C. \& Hur, D. U. (2010). Grupos de geração de renda no Curso Pré-Vestibular Psico-USP: uma experiência de autogestão em um cursinho popular. Cadernos de Psicologia Social do Trabalho, 13(2), 163-175.

10 Gama, C. A. P \& Koda, M Y. (2010). Cooperativismo e reciclagem de resíduos sólidos: uma reflexão a partir da psicanálise de grupos. Cadernos de Psicologia Social do Trabalho, 13(2), 209-224.

11 Esteves, E. G. (2013). “Todos são iguais”, “todos são responsáveis” e "todos estão no mesmo barco": os (des) entendimentos da autogestão cooperativa. Cadernos de Psicologia Social do Trabalho.16(1), 135-148.

12 Martinez, M. C. \&Paraguay, A. I. B. B. (2003). Satisfação e saúde no trabalho: aspectos conceituais e metodológicos. Cadernos de Psicologia Social do Trabalho, 6(1), 59-78.

13 Moreira, F, H., Guizardi, F. L., Rodrigues, J. O. B., Gomes, R. S., Daros, R. F., Andrade, R. B., \& Moraes, T. D. (1999). De elemento a cidadão: transformações no cotidiano do trabalho do policial militar. Cadernos de Psicologia Social do Trabalho, 2(1), 25-38.

14 Rancan, M. \& Giongo, C. R. (2015). "Nunca pensei sobre isso": vivências de trabalho na indústria metalmecânica. Cadernos de Psicologia Social do Trabalho, 18(1), 93-106.

15 Ramalho, C. C., Arruda, F. A. A. M., Sato, L., \& Hamilton, L. F. T.(2008). Viver na baia: dimensões psicossociais da saúde e do controle no trabalho de teleatendimento. Cadernos de Psicologia Social do Trabalho, 11(1), 19-39. 


\section{Referências}

Andrada, C. (2005). O encontro da política com o trabalho: história e repercussões da experiência de autogestão das cooperadas da UNIVENS. Dissertação de Mestrado, Programa de Pós-graduação em Psicologia Social, Universidade de São Paulo, São Paulo/SP.

Andrada, C. (2006). Onde a autogestão acontece: revelações a partir do cotidiano. Cadernos de Psicologia Social do Trabalho, 9(1), 1-14.

Andrada, C. (2013). Trabalho e política no cotidiano da autogestão: o caso da rede Justa Trama. Tese de Doutorado, Programa de Pós-graduação em Psicologia Social, Instituto de Psicologia, Universidade de São Paulo, São Paulo/SP.

Antunes, R. (2009). Os sentidos do trabalho: ensaio sobre a afirmação e a negação do trabalho. São Paulo: Boitempo.

Bardin, L. (2002). Análise de conteúdo (L. A. Reto \& A. Pinheiro, Trads.). Lisboa: Edições 70. Bastos, J. (2014). Saúde mental e trabalho: metassínteses da produção acadêmica no contexto da pós-graduação brasileira. Dissertação de Mestrado, Programa de Pós-graduação em Psicologia, Universidade Federal de Alagoas, Maceió/AL.

Bastos J. A. \& Oliveira, A. A. S. (2016). Revisão sistemática de literatura, estado da arte e matassíntese: a contribuição das estratégias metodológicas de revisão para o desenvolvimento da pesquisa científica no Brasil. In A. Trimboli et al. (Orgs.), Los límites de la clínica (pp. 173-189). Cidade Autônoma de Buenos Aires: AASM.

Bernardo, M. H., Oliveira, F., Souza, H. A., \& Sousa, C. C. (2017). Linhas paralelas: as distintas aproximações da Psicologia em relação ao trabalho. Estudos de Psicologia, 34(1), 14-24.

Bernardo, M. H, Sousa, C. C., Pinzón, J. G. \& Souza, H. A. (2015). A práxis da Psicologia Social do trabalho: reflexões sobre possibilidades de intervenção. In M. C. Coutinho, O. Furtado, \& T. R. Raitz (Orgs.), Psicologia Social e Trabalho: perspectivas criticas (pp. 16-39). Florianópolis: ABRAPSO; Edições do Bosque CFH/UFSC.

Canuto, L. T. (2017). O conceito de infância em artigos brasileiros de Psicologia. Dissertação de Mestrado, Programa de Pós-graduação em Psicologia, Instituto de Psicologia, Universidade Federal de Alagoas, Maceió/AL.

Cadernos de Psicologia Social do Trabalho. (2017). Artigos mais visualizados. Recuperado de https:// analytics.scielo.org/w/accesses/list/articles?journal=1516-3717\&collection=psi

Coutinho, M. C. (2015). Psicologia Social do Trabalho em dois tempos. In M. C. Coutinho, O. Furtado, \& T. R. Raitz (Orgs.), Psicologia social e trabalho: perspectivas criticas (pp. 2-15). Florianópolis: ABRAPSO; Edições do Bosque CFH/UFSC.

Costa, A. L. F. \& Yamamoto, O. H. (2008). Publicação e avaliação de periódicos científicos: paradoxos da avaliação Qualis de Psicologia. Psicologia em Estudo, 13(1), 13-24.

Costa, A. L. F., Amorim, K. M. O., \& Costa, J. P. (2010). Profissão de psicólogo no Brasil: análise da produção científica em artigos. In O. H. Yamamoto\& A. L. F. Costa (Orgs.), Escritos sobre a profissão de psicólogo no Brasil (pp. 33-60). Natal: EDUFRN.

Espíndola, C. R. \&Blay, S. L. (2006). Bulimia e transtorno da compulsão alimentar periódica: revisão sistemática e metassíntese. Revista de Psiquiatria do Rio Grande do Sul, 28(3), 265-275. Esteves, E. G., Bernardo, M. H., \& Sato, L. (2017). Fontes do pensamento e das práticas em Psicologia Social do Trabalho. In M. C. Coutinho, M. H. Bernardo, \& L. Sato (Orgs.),Psicologia Social do Trabalho (pp. 49-80). Petrópolis, RJ: Vozes. (Coleção Psicologia Social).

Esteves, E. G. (2002). Emprego versus trabalho associado: despotismo e política na atividade humana de trabalho. Cadernos de Psicologia Social do Trabalho, 5(1), 51-56.

Lacaz, F. A. C. (2007). O campo saúde do trabalhador: resgatando conhecimentos e práticas sobre as relações trabalho-saúde. Cadernos de Saúde Pública, 23(4), 757-766. 
Mendes, R. \& Dias, E. C. (1991). Da medicina do trabalho à saúde do trabalhador. Revista de Saúde Pública, 25(5), 341-349.

Minayo-Gomes, C. (2011). Campo da Saúde do Trabalhador: trajetória, configuração e transformações. In C. Minayo-Gomes, J. M. H. Machado, \& P. G. L. Pena (Orgs.), Saúde do Trabalhador na Sociedade Brasileira Contemporânea (pp. 23-34). Rio de Janeiro: FIOCRUZ. Oliveira, A. A. S., Lima, C. G. S., \& Morais, K. K. C. (2016). Bibliometria e metassíntese de estudos sobre trabalho publicados na revista Psicologia \& Sociedade. Psicologia \& Sociedade, $28(3), 572-581$.

Oliveira, A. A. S., Trancoso, A. E. R., Bastos, J. A., \& Canuto, L. T. (2015). Metassíntese: apontamentos para sistematização de revisões amplas e crítica interna à produção científica. In $4^{\circ}$ Congresso Ibero-Americano em Investigação Qualitativa, Investigação Qualitativa na Saúde, Anais (pp. 147-152), Aracaju/SE: Universidade Federal de Alagoas. Recuperado de $<\underline{\text { http:// }}$ proceedings.ciaiq.org/index.php/ciaiq2015/article/viewFile/36/34>

Pochmann, M. (2006). Desempregados no Brasil. In R. Antunes (Org.),Riqueza e miséria do trabalho no Brasil (pp. 59-73). São Paulo: Boitempo.

Pochmann, M. (2008). O emprego no desenvolvimento da nação. São Paulo: Boitempo.

Sampaio, R. F. \& Mancine, M. C. (2007). Estudos de revisão sistemática: um guia para síntese criteriosa da evidência científica. Revista Brasileira de Fisioterapia, 11(1), 83-89.

Sandelowski, M., Docherty, S., \&Emden, C. (1997). Focus on Qualitative Methods. Qualitative Metasynthesis: Issues and Techniques. Research in Nursing \& Health, 20(4), 365-337.

Sandelowski, M. \& Barroso, J. (2003). Classifying the findings in qualitative studies. Qual Health Res, 13(7), 905-923.

Sato, L. (2012). Feira livre: organização, trabalho e sociabilidade. São Paulo: Edusp.

Sato, L. (2013). Recuperando o tempo perdido: a psicologia e o trabalho não regulado. Cadernos de Psicologia Social do Trabalho, 16(n.spe.1), 99-110.

Sato, L. (2017). Diferentes faces do trabalho no contexto urbano. In M. C. Coutinho, M. H. Bernardo, \& L. Sato (Orgs.), Psicologia Social do Trabalho (pp. 151-174). Petrópolis, RJ: Vozes. (Coleção Psicologia Social).

Sato, L. \& Esteves, E. G. (2002). Autogestão: possibilidades e ambiguidades de um processo organizativo peculiar. São Paulo: ADS/CUT.

Sato, L., Lacaz, F A. C., \& Bernardo, M. H. (2006). Psicologia e Saúde do trabalhador: práticas e investigações na Saúde Pública de São Paulo. Estudos de Psicologia, 11(3), 281-288.

Sato, L., Oliveira, F., \& Bernardo M. H. (2008). Psicologia social do trabalho e cotidiano: a vivência de trabalhadores em diferentes contextos micropolíticos. Psicología para América Latina, 15. Recuperado de http://pepsic.bvsalud.org/scielo.php?script=sci_arttext\&pid=S1870$350 \times 2008000400010$

Seligmann-Silva, E. (2011). Trabalho e desgaste mental. São Paulo: Cortez.

Singer, P. (2002). Introdução à Economia solidária. São Paulo: Perseu Abramo.

Souza, E. P., Costa, L. M. L., Macedo, R. P., Segantini, S. M., \& Baia, F. R. (2013). Análise dos aspectos autorais dos artigos científicos de três periódicos brasileiros de Psicologia. Fragmentos de Cultura, 23(4), 453-467.

Spink, P. (2009). Microcadeia produtivas e a nanoeconomia: repensando o trabalho decente. Cadernos de Psicologia Social do Trabalho, 12(2), 227-242.

Trancoso, A. E. R. \& Oliveira, A. A. S. (2016). Aspectos do conceito de juventude nas Ciências Humanas e Sociais: análises de teses, dissertações e artigos produzidos de 2007 a 2011. Pesquisas e Práticas Psicossociais, 11(2), 278-294.

Yamamoto, O. H., Menandro, P. R. M., Koller, S. H., Lobianco, A. C., Hutz, C. S., Bueno, J. L. O., \& Guedes, M.C. (2002). Avaliação de periódicos científicos brasileiros da área da Psicologia. Ciência da Informação, 31(2), 163-177. 


\section{JULIANO ALMEIDA BASTOS \\ https://orcid.org/0000-0002-8905-0543}

Graduado e com Mestrado em Psicologia - Universidade Federal de Alagoas. Doutorado em Psicologia Social - Instituto de Psicologia - Universidade de São Paulo, SP.

ENDEREÇO: Centro Universitário Tiradentes - UNIT/ Centro de Psicologia Aplicada - CPA. Av. Comendador Gustavo Paiva, 5017 - Cruz das Almas, Maceió - AL, 57038-000.

E-MAIL:juliusbastos@yahoo.com.br

\section{FLÁVIA MANUELLA UCHÔA DE OLIVEIRA}

https://orcid.org/0000-0002-6847-8436

Graduada em Psicologia - Universidade Federal de Pernambuco. Mestre e Doutoranda em Psicologia Social - Universidade de São Paulo, SP.

E-MAIL: flavia.muo@gmail.com

\begin{tabular}{ll} 
Histórico & Recebido em: 24/09/2018 \\
& Aceito em: 18/07/2019 \\
& Aprovado em:10/09/2019 \\
& Concepção: JAB; FMUO. \\
& Coleta de dados: JAB; FMUO. \\
& Análise de dados: JAB; FMUO. \\
Eontribuição & Elaboração do manuscrito: JAB; FMUO. \\
& Crítico revisões de conteúdo intelectual importante: JAB; FMUO. \\
& Final aprovação do manuscrito: JAB; FMUO. \\
\hline Financiamento & Não houve financiamento para realização deste trabalho. \\
Consentimento de & Não se aplica. Todos os documentos analisados são de acesso livre \\
uso de imagem &
\end{tabular}

